\title{
Analyzing the m-business landscape
}

\author{
Giovanni CAMPONOVO*, Yves PIGNEUR*
}

\begin{abstract}
The m-business landscape never stops to change and the impacts on the mobile market are constant as players reposition themselves on the market according to the new opportunities and threats brought by rapid technological developments. This paper provides a conceptual tool to better understand this player arena and its objective is threefold. The first one is to analyze the role of the key actors using ontology for defining and assessing their business models. The second objective is to analyze and visualize the interaction of actors with each other from a value system perspective. The final objective is to evaluate and represent the dependencies of the actors, their strategies and their convergence or divergence on different issues by using an approach borrowed from policy making.
\end{abstract}

Key words: Electronic trade, Mobile radiocommunication, Economic market, Economic analysis, Modelling, Firm stratégie.

\section{ANALYSE DES ACTEURS ET DES ENJEUX DU COMMERCE PAR TERMINAUX MOBILES}

\section{Résumé}

Le paysage du commerce par terminaux mobiles (m-business) n'arrête pas d'évoluer et les acteurs présents sur ce marché ou champ de bataille ont de la peine à trouver leurs marques. Au dire de certains experts, les opportunités seraient nombreuses; l'histoire récente a rappelé que les menaces et les erreurs de gestion ne manquaient pas. Cet article suggère un outil conceptuel pour mieux appréhender le paysage du m-business sous différents angles. L'objectif est triple: il s'agit dans un premier temps d'analyser le rôle, la position et les perspectives des différents acteurs, à l'aide notamment d'une meilleure compréhension de leur modèle d'entreprise. Cette étude peut alors être prolongée par une analyse et une visualisation des systèmes de valeur et autres configurations d'activités, ainsi que de leur évolution. Le dernier objectif est de proposer quelques pistes pour évaluer et représenter les dépendances entre les acteurs et leurs convergences ou divergences, par rapport à quelques enjeux majeurs de ce marché.

Mots clés : Commerce électronique, Radiocommunication service mobile, Marché économique, Analyse économique, Modélisation, Stratégie entreprise.

*École des HEC, Université de Lausanne, CH-1015 Lausanne (Suisse) e-mail : yves.pigneur@unil.ch 


\section{Contents}

\author{
I. Introduction \\ II. Application framework \\ III. Actors \\ IV. Business models \\ V. Value chain analysis
}

\author{
VI. Major issues and challenges \\ VII. Actor and issue analysis \\ VIII. Scenario planning \\ IX. Conclusion \\ References (46 ref.)
}

\section{INTRODUCTION}

Nowadays rapid developments in wireless networks and mobile information systems, are constantly emerging and can become a major stake in the e-business game, as illustrated by large public- or private-funded research projects, recent reports [29], telecom scenarios [15], strategic conferences [13], and other books of vision [45]. As an illustration of these dramatic changes, a "hot" topic debated in the wireless community is the "ad hoc networks" which runs solely by the operation of end-users, without ground infrastructure. The research described in this paper is precisely related to a long-term research program, called "Terminodes", which aims at studying and prototyping large-scale infrastructure-less, self-organized networks [20].

There are several ways to come to an assessment of the mobile technology, and to identify research issues in m-business. Well-known authors of the IS community recently published research directions and agendas. Varshney and Vetter [43] propose a 4-level integrated framework for mobile commerce, based on important classes of applications such as finance, advertising, and logistics. They also discuss how existing and emerging wireless networks can support networking requirements of these applications. Pedersen and Ling [32] provide an adoption framework based on the end-user viewed as a technology user, a consumer, and a network member, respectively. He also suggests applying the framework to design guidelines that can be used by market players to predict end-user adoption of $\mathrm{m}$-commerce services. Lyytinen and Yoo [28] suggest a framework, which identifies research issues in nomadic computing environment at the individual, the team, the organizational, and the interorganizational levels. They assess the opportunities and challenges for research into each area at the level of design, use and adoption, and impacts. Lehner and Watson [27] concentrate on a stakeholder perspective, services and applications perspective, and a market player's institutional perspective. In the latter, they propose relevant research problems such as the business models, the useful alliances and the driving forces for cooperation, the interaction between market players, among others.

Moreover, some researchers such as Bria et al. [5] remind that the infrastructure deployment is a slow and costly process, in a very uncertain future that demands a long-range strategic planning. The same is true for the broad adoption of new behaviors and practices. Therefore, for guiding research, they suggest to use a scenario-based forecasting approach, based on global trends in technology, economy and politics, and verified among leading industrials and scientists.

This paper will focus on the mobile market player's arena as suggested by [27], and at the intersection of the inter-organizational and the impact levels in the framework provided by [28]. The paper aims at sketching a conceptual tool for analyzing and visualizing the key 
players, their business models, their interactions and their dependencies. The latter issue should be the first, indispensable, step towards a more general scenario approach with its formal analysis and field interviews, as advocated by [17].

The next section will provide a framework or general architecture for the m-business systems or solutions, which covers the user, needs, the service and content provided, the devices and information technology used, the communication network adopted, and the regulatory environment. The three next sections provide the reader with an institutional perspective with the key players of the m-business market, present an ontology for assessing their business models, and cope with a value system analysis for cooperation. Finally, the three last sections will propose to emphasize some major issues in m-business, to use a policy making approach for modeling the position and the power of the competitive players on these issues, and to adopt a scenario planning approach for opening some futures in this area.

\section{APPLICATION FRAMEWORK}

We propose to classify the applications, the actors and the issues facing the m-business industry, according to the framework illustrated in Figure 1. At the center of the mobile business world is the user, who have mobility-related needs. In order to fulfill these needs, three complementary supporting blocks are required: network and communication (including the different networks that provide transmission capabilities), device and information technology (including mobile devices, servers and platforms) and the services and content (including applications, content and supporting services). These blocks are then constrained by regulation and social context.

The needs can address people mobility problems and require nomadic information environments at the individual, the team, the organizational, and inter-organizational levels, com-

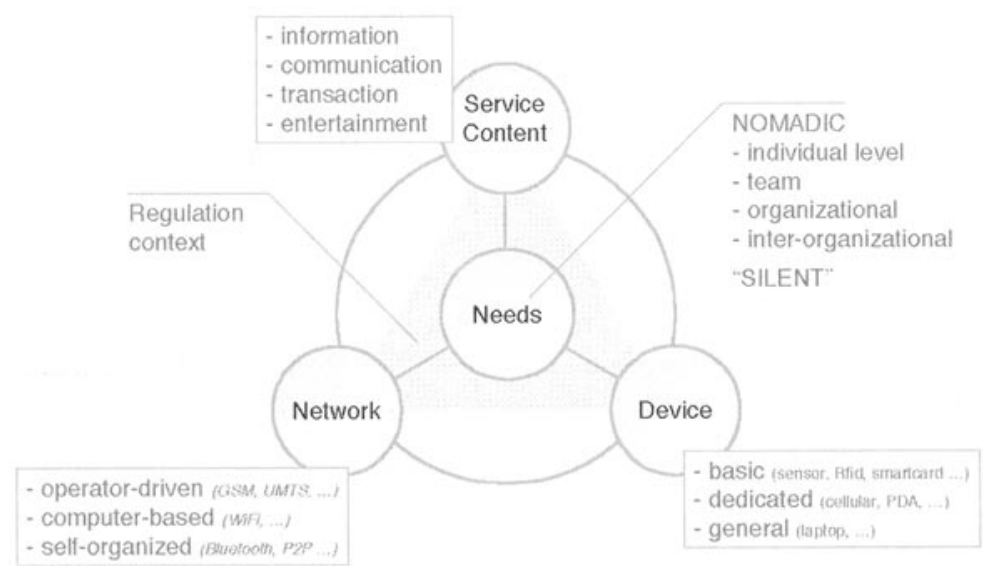

Fig. 1, - m-business application framework

Modèle d'applications mobiles. 
prising both service or infrastructure development, as suggested by Lyytinen [28]. The needs can also correspond to a silent commerce solution, which uses wireless mobile communications, advanced tagging, and sensor technologies, without human interaction, to improve supply chain management, to better manage inventory, or to track physical items.

Mobile services and content allow access to information (news, weather, phone books, catalogues), communication (SMs, e-mail, alerts, promotion, child tracking), transaction (auction, sales, ticketing, brokerage, banking, payment). They also allow entertainment (games, gambling, ring tone, MP3, photographs, video-clips). In the business segment, they could improve workforce management (calendar, mail, groupware), supply chain management (fleet management, item tracking), and customer relationship management (sales, services), as synthesized among others by [29].

Mobile business solutions could be deployed for different kinds of devices and IT infrastructure (server, operating systems, software platform). The devices could be basic (sensor, Rfid, smart card), dedicated (cellular, PDA, bar code scanner), or general purpose (laptop).

A broad range of communication technology is available for the network infrastructure required by a mobile business solution: operator-driven networks (GSM, GPRS, UMTS), computer-based and Internet networks (WLAN), and self-organized networks (Bluetooth, sensor, ad hoc, Manet).

The regulation environment is key in most $\mathrm{m}$-business solutions and addresses standardization, spectrum availability, security, privacy, safety, and intellectual property right (IPR) concerns.

\section{ACTORS}

The wireless market is highly fragmented and has witnessed a large number of market players to offer an end-to-end solution between the content owner and the end-user ${ }^{1}$. Understanding the role of the players is important. Many experts [27, 29, 11] share similar categorizations of the mobile market key players in m-business, which include, as shown on Figure 2:

- In the device \& technology area, the primary participants are access device manufacturers. The secondary players are device retailers, component makers, network equipment vendors, enabling technology vendors (for operating systems, browsers, embedded software, antennas, battery), and platform vendors.

- In the service \& content area, the primary actors are application providers, content providers and content aggregators. Portals are also important players in this category. The other actors are application developers, middleware developers, and system integrators. Some distinguish content owners. E-business players implementing a mobile strategy and professional service providers, such as the consultancies, are also active in this sector.

- In the network \& access area, the primary actors are mobile network operators (MNO) or carriers, and Internet service providers. If mobile network operators certainly are among the most key players in the cellular and other GSM or UMTS area, we can observe the first self-organized networks, WiFi networks, and large-scale wireless local area networks $[1,42]$.

1. The situation in the Japanese market is different, but we consider that difference to be cultural-specific and therefore not relevant for this analysis. 


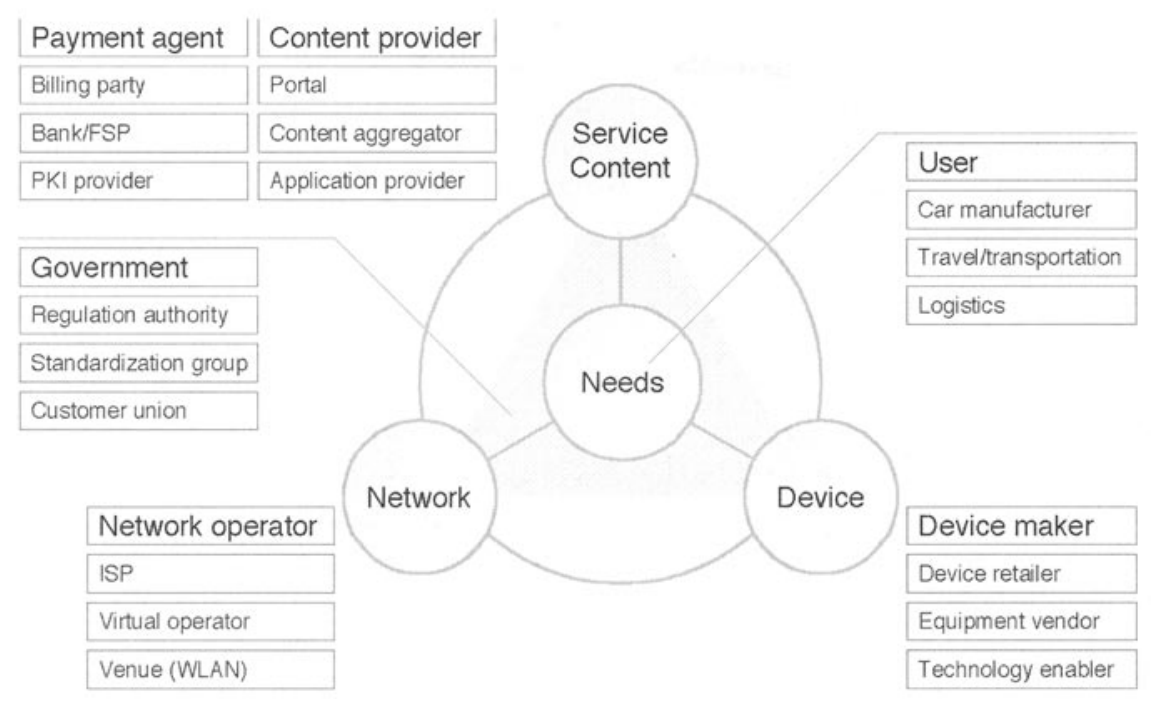

Fia. 2. - Examples of key players (see Appendix 1).

Exemples d'acteurs clés.

According to Giussani [16] and Durlacher [29], some new actors are emerging such as virtual operators (who provide services through networks of other operators), multi-access portals (who enable customers to access different personalized services through many communication channels), wireless application service providers (who deploy, manage, and remotely host a range of applications or services for enterprises and operators), and wireless infrastructure service providers (who provide the "software intelligence" layer necessary to keep together infrastructure that is technologically increasingly heterogeneous).

End-users, corporate or consumer, are also playing in this game. Moreover, it could be necessary to consider some "vertical" players such as found in the travel/transportation, logistics, healthcare and retail sectors. Car electronics is a major topic from this point of view.

Other players, which are mentioned by some of the experts, are payment agents [26], equivalent to financial service providers, billing parties, or payment service providers, for some others. One observer [11] adds advertising companies as actors. Very few authors [27] explicitly introduce government, regulation authorities, and standardization groups as players. It seems that no expert mentions consumer groups as actors. Yet some of them are very active against electronic smog, for example, and will have a true impact on some decision, such as the deployment of UMTS infrastructure and antennas.

Finally, if we consider the alternative approach of the Wireless Local Area Network (WLAN), the actors are slightly different from the cellular ones, such as GSM or UMTS. Hardware suppliers, service-provisioning players, roaming brokers, and wireless Internet service providers are certainly the main players. But the "venues" such as airports, hotels and conference centers, sport stadiums, hospitals are to be also considered as actors $[1,42]$. The same is true for Bluetooth technology, which prefigures more ambitious ad hoc networks. The actors and 
their roles are different; i.e. mobile network operators are no longer a key player in such infrastructure-less environment $[25,36]$.

A last observation: if many experts mention some company names for illustrating the key players they present, most of them speak about generic actors; rare are the authors which focus their research studies on the true actors or companies of the m-mobile market [24].

\section{BUSINESS MODELS}

We believe that analyzing the roles and relationships of the different actors participating in the mobile field is an important step in better understanding the mobile business landscape. For assessing the role of the different m-business key players, it is recommended to briefly but clearly describe their business models. In this research, we adopted an ontology or framework for e-business models we conceived and verified [31].

It has already been shown that a formal e-business model is essential in an increasingly dynamic and uncertain business environment, such as the m-commerce. The process of modeling an e-business model, helps identifying and understanding the relevant elements in a specific domain, and the relationships between them. The use of formalized e-business models using ontology helps managers easily communicate and share their understanding of an e-business among other stakeholders. Using e-business models as a foundation for discussion facilitates change. A formalized e-business model can help identifying the relevant indicators of a Balanced Scorecard. Business models can help managers simulate e-businesses and learn about them. This is a way of doing risk free experiments, without endangering an organization.

The e-business model ontology we adopted is founded on four main pillars, as illustrated on Figure 3:

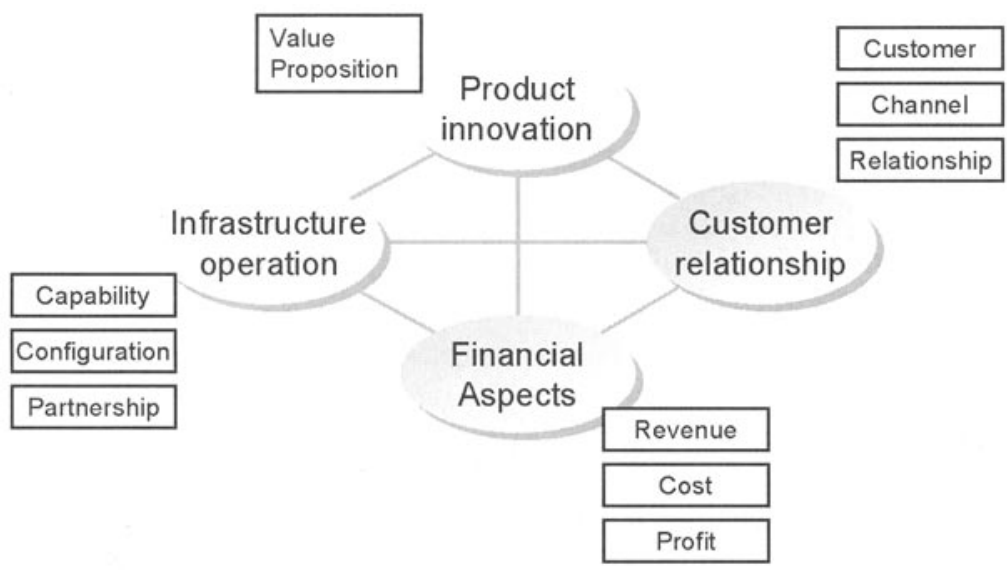

FIG. 3. - m-business model framework.

Composants d'un modèle d'entreprise. 
- The product innovation element covers all aspects related to the offering of the firm. This comprises not only its products and services but also the manner in which it differentiates itself from its competitors. The element product innovation is mainly based on the value proposition, the offerings and the benefices the firm proposes to its customers. The firm has to provide specific capabilities or competencies in order to deliver this offering.

- The customer relationship element describes who are the customers and the way a firm goes to market and gets in touch with its customers. This element consists of the target customers, the distribution channels in order to feel \& serve customers, and the customer relationship or equity in order to get \& keep customers. The later justifies some personalization and trust mechanisms that are becoming essential in an increasingly "virtual" business world.

- The infrastructure management describes the value configuration that is necessary in order to deliver the firms offering and to maintain a customer relationship. It is composed of the activity configuration (value chain), the in-house capabilities and resources, and the firm's partner network to fulfill these activities.

- The element financial aspect is the culmination of an e-business model. The best products and services and the finest customer relationship are only valuable to a firm if it guarantees long-term financial success. The financial aspects element is composed of the company's revenue model and its cost structure, which finally define the profit \& loss of a firm.

Figure 4 illustrates a couple of possible aspects of the business model for an APPLICATION PROVIDER, such as Aspiro in Sweden [24].

\begin{tabular}{|c|c|}
\hline Value proposition & $\begin{array}{l}\text { Offers services designed to satisfy the individual's needs for entertainment (game, ring } \\
\text { tones, horoscopes), information (news, weather reports, translation service), and commu- } \\
\text { nication (unified messaging) via mobile media }\end{array}$ \\
\hline Target customers & Mobile network operators, portals, system integrators \\
\hline Activities & $\ldots$ \\
\hline Partners & Device makers for distribution agreement \\
\hline Revenues & $\begin{array}{l}\text { Selling a whole system (with maintenance), hosting a solution with continuous stream of } \\
\text { payment, revenues sharing with operators }\end{array}$ \\
\hline
\end{tabular}

FIG. 4. - Extract of a business model.

Illustration d'un modele d'entreprise.

\section{VALUE CHAIN ANALYSIS}

Since no single player can provide its customers with an end-to-end solution on its own, fostering viable alliances and actors networks is a key challenge of $\mathrm{m}$-business. Therefore most of the firms are partnering, taking equity interest in others, signing contracts, or purchasing solutions to create value and provide mobile customer with value-added services. Partnership management is becoming a core competence of the $\mathrm{m}$-business players; the $\mathrm{m}$ business space will be completely built on partnerships. 
Therefore it is not enough to examine the actor's role. The relationships and interactions among the actors have to be assessed too. To define the value creation process in such an actor network, it is appropriate to apply the Porter value chain framework and its extension, such as defined by Stabell and Fjeldstad [37]. They extend the idea of the value chain with the value shop and the value network. Former describes the value creation process of service providers, whereas latter describes brokering and intermediary activities.

As an illustration, the value network is particularly adequate to define the activities of a MOBILE NETWORK OPERATOR. The model suggest to distinguish the following three main set of activities:

- The network promotion and contract management activities, or customer care in the Telecomm Operations Map (TOM): sales, order handling, problem handling, customer QoS management, and invoicing \& collection.

- The service provisioning activities, or service development and operations in the TOM: service planning/development, service configuration, service problem resolution, service quality management, and rating $\&$ discounting.

- The infrastructure operation activities, or network and systems management in the TOM: network planning and development, network provisioning, network inventory management, network maintenance and restoration, and network data management.

Value chain analysis has been used for assessing the wireless telecommunication industry [7], mobile Internet content providers [11], or the Bluetooth emergence [36]. This kind of analysis helps identifying key activities of the actors, analyze the value they create, map the exchanges of flows into and out of activities and actors, and improve resource allocation. The model can be used to visualize the interactions between actors.

For exploring the value networks and their collaborating actors in the $\mathrm{m}$-business industry, we adopted a similar model [34], which we developed for designing situations in the context of mutations, such as alliance, merger, acquisition, and dismantlement. The model consists of the following concepts: activity, value flow entering and leaving activities, rule, and value configuration (the set of the activities performed by an actor). The model also integrates a decision process for migrating from one activity configuration to another, when recombining activities among actors. Figure 5 illustrates the exchange of flows and values between some $m$-business participants.

Based on this simple illustration and as an example of mutation in an actor network, we could observe that the two actors should decide together to move the Service distribution activity from the Mobile Network Operator to the Content Aggregator value configuration for better serving the customer.

Many other alternative models have been proposed to define and analyze value chains and value networks. For example, Gordijn et al. [18] propose a formalized onto$\operatorname{logy}$ based on the value chain model. His $e^{3}$-value ${ }^{T M}$ model contains concepts, relations, and constraints, to describe actors, alliances between them, and the exchange of objects of value, value-adding activities, and the value interfaces between them. This model is more rigorous than the original value chain and allows completeness and consistency checks. 


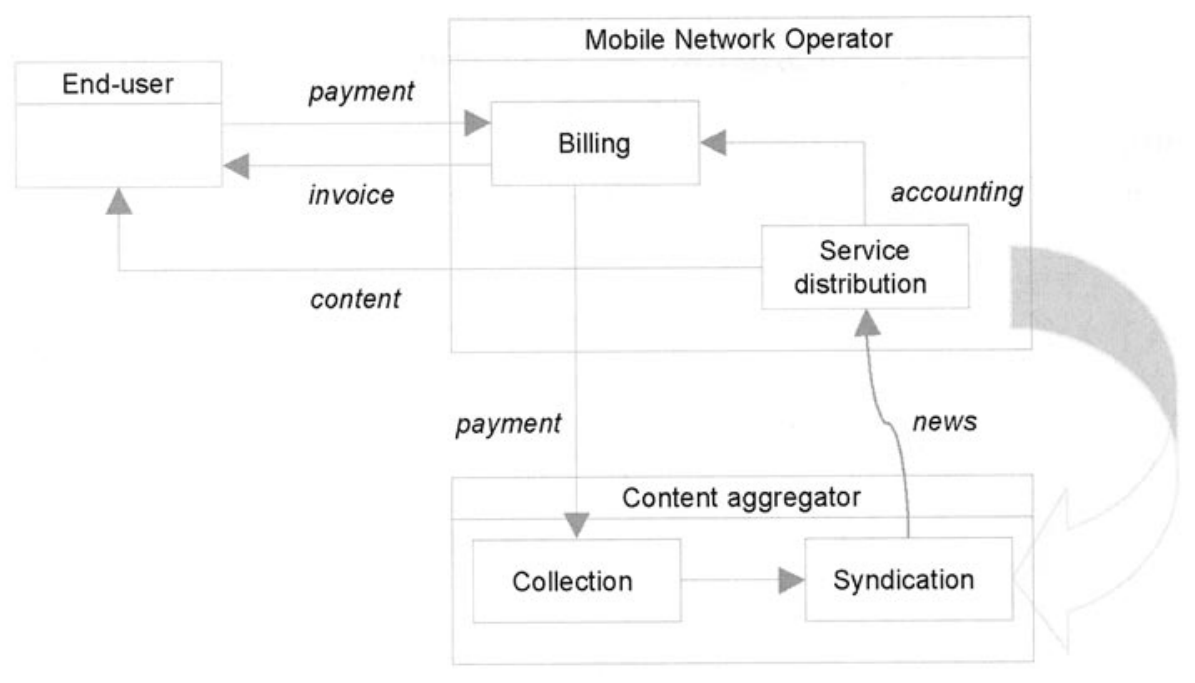

FiG. 5. - Extract of a value configuration.

Illustration d'une configuration d'activités.

\section{MAJOR ISSUES AND CHALLENGES}

The emerging m-business environment presents a new set of issues or challenges facing the industry. Issues are ideas, topics, and problems open to discussion or dispute, which are critical for the $\mathrm{m}$-business industry development, that can be investigated and on which players can speculate and have different positions. Although mobile business is inherently a technological domain, it is expected to have profound impacts upon the people's ordinary life, the businesses and the society as a whole.

Focusing exclusively on technology development issues would therefore be too limiting. An interesting approach is adopted by Tarasewich [39], who identifies issues in mobile ecommerce and finds categories that include technological (both device and infrastructure) issues, application issues, and areas for future research.

Bria et al. [5] also suggest issues, based on their vision of "mobile multimedia to all at today's price for fixed telephony" and their working assumptions: tele-presence, information anytime and anywhere, inter-machine communication, security, one-stop shopping, nonhomogeneous infrastructure, public and private access mixed, ad-hoc unlicensed operation, multi-mode access ports in public systems, and large range of bandwidth for terminals.

Another report from the KTH [22] identifies a number of critical challenges facing industry: the threat of disruptive technology, the low spectrum release, 3G debt threat for Telco, the stampeding system complexity, radiation problem, better battery capacity, cheaper infrastructure and viable business models, a phone for everyone.

Recent European Union conference proceedings [13] also suggest ambient intelligence (or user in foreground), sustainable human development, cyber-terrorism, Internet control, information warfare, digital divide, democracy, and generation gap. Another European 
Union report [44] proposes the following strategic challenges: vanishing revenue streams, from selling capacity to "monetising" content, increased convergence \& competition, expanding core business \& climbing up the value chain, reaching critical mass, and increasing concentration and competition. Finally, the MobiCom European project [16] identifies battlefields: access to customers, dominance within the value chain, role of public sector, IPR, standards, privacy, alternative technology, social needs fulfillment, and seamless roaming.

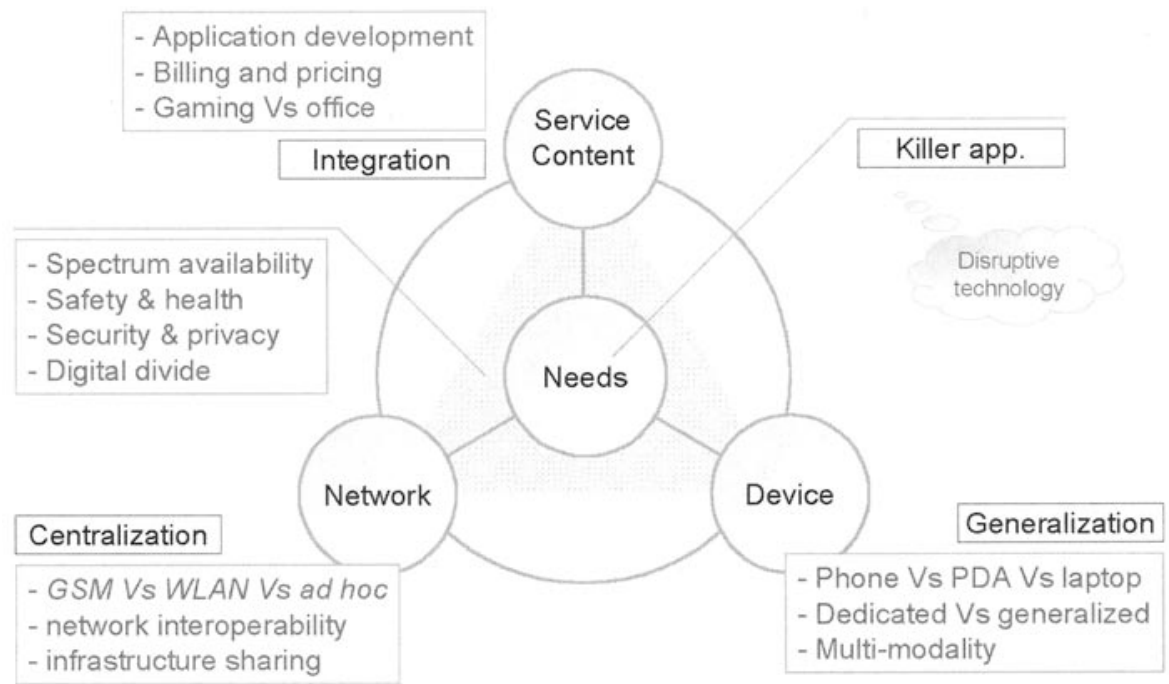

FIG. 6. - Examples of key issues for the future of m-business.

Quelques enjeux du commerce mobile.

Based on the framework we suggested in Section II, we propose to identify service, device, network and regulatory issues.

\section{User needs issues}

Killer app or Wireless Application demand. Wireless networks allow applications to use a set of unique advantages of mobile communications such as ubiquity, reach ability, security, convenience, localization, instant connectivity and personalization. What application will exploit these unique characteristics to provide sufficient value to drive demand and for which customers will pay remains very uncertain. B2B applications supporting mobile workforce (i.e. sales forces and field personnel) or logistics (supply chain management, fleet management) might be more successful, at least initially. 


\section{Service and content issues: integration is key}

Application development. Development of robust wireless applications is characterized by a great complexity. Service provisioning and content delivery also involve a great number of partners and require integration of different systems (i.e. positioning and billing systems of network operators). Middleware solutions, open platforms and standards are expected to be increasingly important as the diversity of the underlying networks and devices increases.

Billing and pricing issues. Pricing policy is a critical issue in the successful diffusion of mobile applications. They have to be defined considering network externalities and switching costs. With the arrival of packed based networks, new pricing mechanism can be decided such as flat rates, per byte pricing and value-based pricing (i.e. the model adopted by i-mode). Sophisticated pricing policy means adequate billing systems, a key asset in the emerging $\mathrm{m}$-business landscape. Mobile operators already have sophisticated billing systems in place. Other players that might offer billing services include credit card companies, banks and new entrants.

Standards. Standards historically played an important role in the telecommunication industry; so did they in the IT transaction environment. It is argued that standards will be an even more important issue in the m-business, at many levels: software development platform (i.e. .NET/Stinger Vs. J2E/Java), electronic data interchange (XML \& EDI), etc.

\section{Device and technology issues: convergence is key}

Phone vs. PDA vs. laptop. The kind of device is an important issue, as they have different characteristics and capabilities that make them not equally suitable for different kinds of applications. Today, mobile devices range from mobile phones to PDAs to notebooks equipped with wireless cards. Some authors expect a proliferation of different forms of devices, while other expects a single dominant form.

Dedicated vs. generic. What will be the evolution? Single generic devices? Specific devices, dedicated to a specific task (i.e. inventory management)? Modular devices? Arrays of single purpose terminals interoperating in personal-area networks, such as Bluetooth [17].

Multi-modality. The deployment of different kinds of networks justifies the needs for multi-modal devices, able to operate with different network technologies; with devices supporting different generation of cellular networks (i.e. GSM/UMTS phones), but also WLAN/cellular network capabilities. Multimode device should ideally transparently choose the best network according to user preferences, application requirements and networks availability.

\section{Network issues: operator-driven vs. self-organization}

GSM vs. WLAN vs. ad hoc. Self-organized networks, such as WLAN and ad hoc networks, could be a disruptive technology in the operator-driven GSM/UMTs story. The so-called WiFi and other public WLAN hotspots started to emerge in venues such as airports and hotels. Roaming brokers already started to create wireless broadband networks based on clusters of wLANs [18]. Wide area multi-hop ad hoc networks [17] are another alternative on the long range. 
Network interoperability. The future telecom landscape will probably be characterized by the simultaneous operation of different complementary network types, characterized by different coverage that make them more or less suitable in different usage contexts. In such an environment, interoperability between the different networks (probably at the Internet Protocol level), seamless roaming, and sometimes handovers will be key success factors for the uptake of mobile applications.

Infrastructure sharing. Due to the $3 \mathrm{G}$ Telco debt threat and also to the increasing opposition from consumer groups against new antennas, infrastructure-sharing agreements between operators would provide potential significant savings.

\section{Regulation issues}

Spectrum availability. Spectrum is a finite, rare and irreproducible resource. In the hype period, it was forecasted to be insufficient to cover the whole demand of new services, and researchers saw the need to improve spectrum utilization efficiency (dynamic spectrum allocation, spectrum sharing agreements, better signal coding, compression, and smart antennas) or find new spectrum ranges (DTB/DAB spectrum, new frequencies ranges, $U$ ). More recently, some experts started to see an opposite problem of insufficient demand, causing network over-capacity and the need for operators to open up their networks to virtual operators. Another spectrum important issue is the future regulation of the actually unregulated $2 \mathrm{GHz}$ band used by WLAN, Bluetooth and industrial appliances.

Safety and health concerns. The effects of the wireless networks on human health are not yet known and there is a risk of rejection of technology and legal disputes of damage repairing. The cost of antenna sites may rise enormously, due to both health and aesthetical concerns, and operators might have to share the infrastructure with others or reduce the number of new base station to deploy (i.e. only in urban areas).

Security, privacy and $I P R$. Security could be ensured with PKI, digital encryption, frequency hopping, and Trusted Third Parties, in order to reduce the fear of cyber trading. Privacy is a controversial issue for finding a balance between the degree of intimacy that can be given away by the consumers and the amount of consumer information needed for efficient marketing. Intellectual Property Right (IPR) is also an issue between content providers, content creators (artists), consumers, operators, software developers, as the technology challenges existing IPR models. [8]

Digital divide and social needs fulfilment. There are a large number of people who don't yet have a portable device. Has IT policy making to focus on them and to enforce solutions (universal service availability, phone for everyone) to satisfy basic communication needs?

\section{ACTOR AND ISSUE ANALYSIS}

A classical starting point for exploring the competitiveness of a market and the power of the participants is Porter's Five Forces model. The model can be used to assess the firm rivalry, the supplier power, and the buyer power, as well as the new entrants and the market substitutes. 
This model is not sufficient to clearly visualize the key players arena and its evolution. We could explore some other approaches inherited from sociology, information systems engineering, industrial prospective, and policymaking.

Lyytinen and Yoo [28] suggest to use the Actor-Network Theory (ANT), initially developed by a sociologist (B. Latour) and already used in the IS community for assessing socio-technical innovation [41]. This theory draws on the strengths of qualitative research and extends ethnography to assess how technology is socially constructed or aligned. The analysis assumes that the stakeholder interactions have to be investigated, in terms of extent of communication, power, trust, resource control, irreversibility of position, and influence (inhibitors and promoters).

The notion of goal is increasingly being used in requirement engineering today, as advocated by [46]. The $i^{*}$ model allows to describe networks of intentional relationships among actors. Actors depend on each other for goals to be achieved, tasks to be performed, and resources to be furnished. These dependencies are intentional in that they are based on underlying concepts such as goal, ability, commitment, belief, and so on. The model also describes the reasoning that each actor has about her/his relationships with other actors, her/his alternative means to achieve goals. Yu et al. [46] explained that actors are strategic because they seek to protect their interests and they evaluate their social relationships in terms of opportunities, and vulnerabilities that they may bring.

In industrial forecasting, the Mactor analytical tool $[4,17]$ provides the observer with an interesting approach to analyze the actor's strategies and moves, confront their plans, and examine the balance of power between them. Mainly based on the position of each actor on each strategic issues of the battlefield (in favor of or opposed to an objective), the importance they assess to the outcome of each issue, and their power relationships on each other, a matrix calculus allows to detect, visualize and evaluate the influence dependencies, the divergences and the convergences over goals of the actors.

Mueller and Lovelock [30] exploit a game-theoretic approach for analyzing the way four Chinese players interacted over access to foreign investment in telecommunication services.

Having also adopted a game-theoretic practice, some authors in policy making $[6,38]$ argue that it is reasonable to analyze policy choices using expected utility calculations. The objective of such decision models is to attach a probability statement to alternate actions and reduce risk of undesirable outcomes. Allas et al. [2] simplify theses decision models based on game theory for supporting negotiators in multiparty deals, helping them to predict the behavior of the stakeholders and guiding them to favorable strategies.

In the last three families of models, experts are asked to specify the following elements for each actor on each issue:

- The actor's stated position regarding the issue, given his preference and his interest

- The potential influence (power or clout) of the actor over the decision outcome on this issue

- The actor's interest or salience in the outcome of the decision, indicating the importance he will attach to the realization of his position.

Based on these input, the model [2] can calculate and visualize the (un-) stability of the situation; the actor categorization with divergence and convergence; the decision landscape with the followers, the shapers, the influencers and the bystanders, when crossing the salience and the influence of the actors; the relationship analysis with the bargainers, the deal breakers and the easy winners for some issues. 


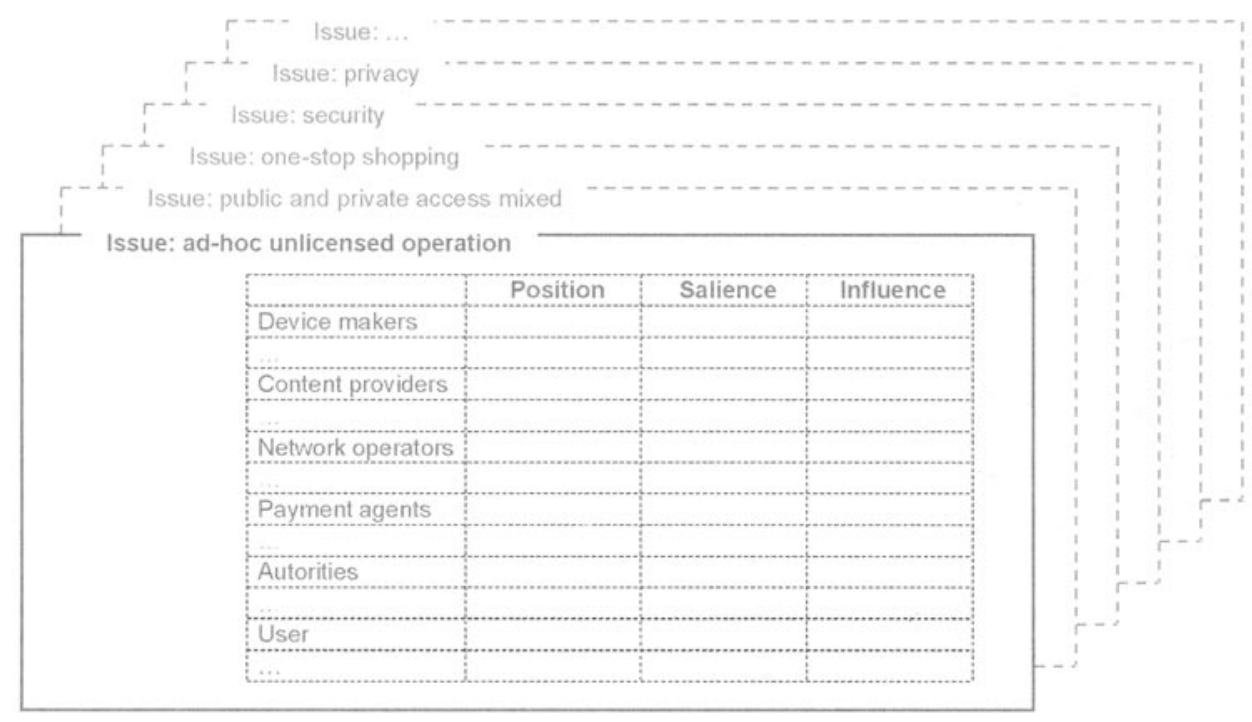

FIG. 7. - Position of actors on issues (Allas, 2001).

Position des acteurs par rapport aux enjeux (exemple).

We have to list actors and issues necessary for assessing the dependencies of actors with each other. The next step of this research is to assess the position, salience and influence for each actor for each issue, based on expert interviews. Figure 7 illustrates the matrix defining the position, the salience and the power for each m-business actor, identified in section 3 , on each issue, suggested in the previous section. This matrix is the input for calculating and visualizing the position landscape, the dependencies, and the relationships between actors.

\section{SCENARIO PLANNING}

Since the future in the m-business area is so uncertain and the pace of development so fast [9], a scenario-based forecasting approach could be helpful before defining a strategy of adoption, deployment, and management of mobile e-business solutions. Traditional strategic planning methods are not suitable, because they are based on the assumption that the future can be predicted accurately enough to choose a clear strategic direction [8]. A suitable alternative is a scenario-planning approach, which is well suited to address the high levels of complexity and uncertainty observed in this industry.

Scenarios are descriptions of possible or probable futures, detecting and understanding the weak signals and the emerging discontinuities on the way to the foreseen future. Scenario planning follows a systematic, interactive, and imaginative process. The exercise finish with 3 or 4 scenarios presenting plausible and surprising alternative future, instead of extrapola- 
ting current trends from the present like traditional forecasting. Scenario planning should facilitate strategy and decision under uncertainty.

There are a variety of different methods for designing scenarios [17]. Developed in the so-called French School [16], the structural scenario method aims at constructing representations of probable futures as well as the formal rules and routes that lead there, using a mixture of facilitated group interaction and formal quantitative techniques (prospective workshop, structural analysis, analysis of actor's strategies, morphological analysis, expert inquiries). On the other way, the Global Business Network approach, popularized by Shell in the 70's [39], is much more informal and based on the key factors, the driving forces, and the alternative visions gathered by a team of experts during scenario workshops. To prepare and analyze the scenario, a dynamic simulation modeling approach [7] is sometimes adopted. The simulated models should reveal what could happen if actors adopt different strategies under different markets and competitive conditions.

Many research teams and authors applied different scenario approaches for assessing $\mathrm{m}$ business:

Lai et al. [26] present three potential mobile market structures: Super Operator, in which the operator leverages its ownership of the access network; Intimate Seller, in which buyers have separate relationships with device manufacturers, wireless network operators and individual; and Brand Bureau, in which content providers and aggregators form partnerships to deliver integrated offerings to buyers.

Bria, Flament et al. [5, 15] develops scenarios, based on global trends in technology, economy and politics, and verified using a Delphi survey among leading industrials and scientists. In the Big Brother scenario, regulation and government intervention are called to ensure integrity and security. In the Anything goes scenario, mobile solutions, such as WLAN, are introduced at a very fast pace, central control decrease, access is more or less free, and defacto standards dominates. In the Pocket-computing scenario, the technological development is fast, but economical and educational differences split the population between those who can have total access and those who cannot.

Another more recent report from the same research location (KTH in Sweden) [22] deals with the state of the wireless industry in 2015. In Wireless Explosion \& Creative Destruction, wireless services and technology develops very rapidly, open architectures based on the IP protocol are becoming widespread, and the datacom industry is in pretty good shape on the market battlefield. In Slow Motion, an economic recession is observed and electromagnetic radiation from mobile devices is reported harmful, forcing industry to refocus on more harmless technologies. Rediscovering Harmony involves a significant lifestyle shift implying fewer wireless services than expected. In the Big Moguls \& Snoopy Governments, a few large companies dominate the wireless market and, together with the governments, control the communication and media industry.

The Mobicom research project [8] exploits a Structural Scenario method [4] to depict four alternative future states in mobile commerce. In the Business as usual scenario, the growth is slow and the market resembles the today situation. In the Consensus of institutions for controlled growth scenario, the big players control the development of infrastructure, standards, and services for m-business. In the Telecom is backing off scenario, Telco operators agree upon seamless roaming, new entrants are coming in the game, and consumers face a growing number of options for getting access to the Internet. In the Deregulated liberalistic markets scenario, the regulator is active in creating a liberal mobile commerce policy, in order to boost competition. 


\section{CONCLUSION: TOWARDS A MOBILE MARKET SCORECARD}

The approach sketched in this paper should allow to better assessing the actor game in the m-business industry. Compared to similar recent papers [27, 28, 43], this one suggested a more elaborated way to deal with the game of the stakeholders in m-commerce. It proposed an original framework to describe and compare them taking into consideration their business models, their inter-organizational systems and their relative influence.

The objective of the future research is twofold. On one hand, this research project plans to keep the picture of the m-business battlefield up-to-date. If the study is regularly actualized, this research should confirm or invalidate the hypothesis affirmed by [10] "wireless operators are best placed to assume the role of kingmaker because they control the wireless network and own the subscriber relationship". If the trend towards self-organized networks, which we presented at the beginning with the ad hoc networks, Bluetooth technology and other WLANS, is confirmed in the future, this could bring interesting changes in the inter-relationships and balance of power between actors.

Because we cannot fully understand a complex environment such as the mobile business landscape, we have to rely on representations of it. Different representations of the same reality are desirable, so that each of them captures a different facet of the reality. Putting them together should give a more comprehensive view of the landscape. Inspired by the work on the Balanced Scorecard defined by Kaplan and Norton, we suggest defining a Mobile Market Scorecard, illustrated in Figure 8, with four interdependent perspectives. For each perspective, we suggest appropriate observation tools.

The market perspective focuses on the demand side of the wireless industry, by looking at the customers' mobility-related needs and the mobile services conceived to satisfy them (see section 2). This perspective is investigated through market surveys and, adoption studies [32].

The industry perspective focuses on the supply side of the wireless industry, by analyzing the key actors, the relationships among them and the wireless industry structure. This perspective is investigated using industry analysis methods such as competitive analysis, applying the value chain framework and observing the actors' business models, as sketched in sections 3,4 , and 5 .

The innovation perspective focuses on the technological side of the wireless industry, by analyzing the key issues that will shape the future evolution of the industry. Issues relate to technology, business, societal, and regulatory context. This perspective is investigated using a scenario planning method based on formalized methods such as multi-actors decision models, as tackled in sections 6 to 8 .

The financial perspective focuses on the financial side of the wireless industry, by looking at the sustainability and attractiveness, of the wireless industry. This perspective is investigated through financial analyses, which can be made on the different technological solutions, actors' business models and services.

Our final objective is to build an intelligence information system based on the Market Scorecard framework. This information system could enable to scan the wireless landscape at regular intervals and build representations to follow its evolution through time. 


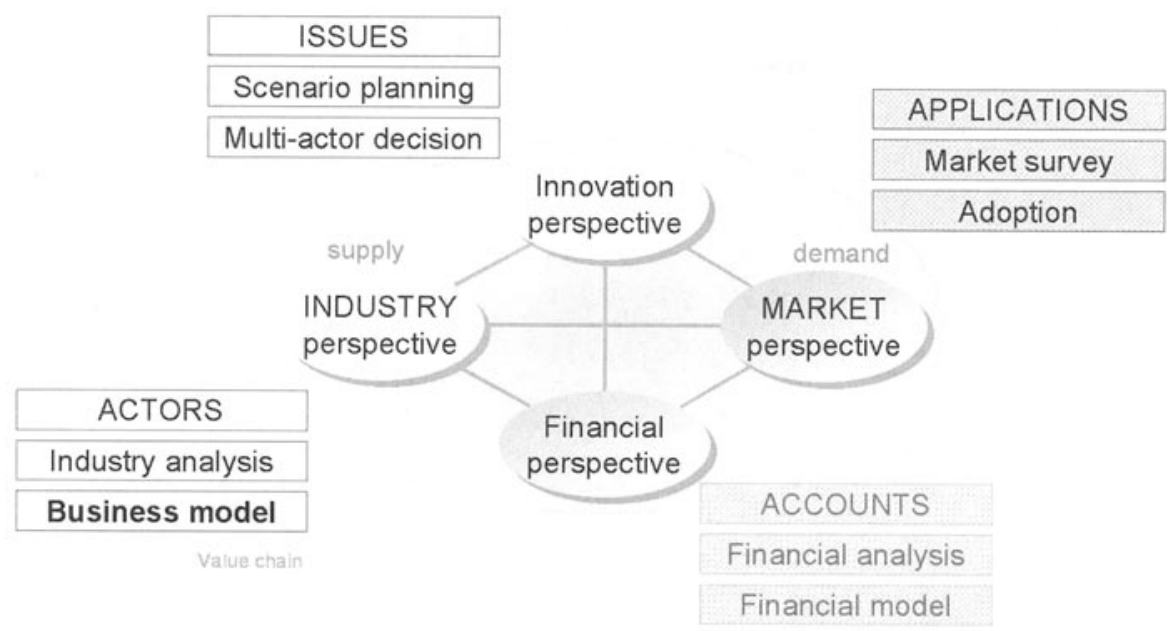

FIG. 8. - m-Market Scorecard.

Tableau de bord du marché du mobile.

\section{Acknowledgements}

The work presented in this paper was partially supported by the National Competence Center in Research on Mobile Information and Communication Systems (NCCR-MICS), a center supported by the Swiss National Science Foundation under grant number 5005-67322, and was carried out in the University of Lausanne.

[1] Alvén (D.), Arjunanpillat (R.), Farhang (R.), Kansal (S.), Khan (N.), Leufvén (U.), wlan hotspots -connect the dots for a wireless future final report for Ericsson business innovation and Telia research. Royal Institute of Technology, Stockholm (2001), $102 \mathrm{p}$.

[2] Allas (T.), Georgiades (N.), New tools for negociators. McKinsey Quarterly. 2 (2001), 86-97.

[3] Amblard (F.), Modèles multi-agents pour la decision collective. Thesis Université de Montpellier (1999).

[4] Arcade (J.), Godet (M.), Meunier (F.), Roubelat (F.), Structural analysis with the Micmac method \& actors" strategy with MACTOR method. Glenn, J. (ed), Futures Research Methodology, American Council for the United Nations University: The Millennium Project (1999).

[5] Bria (A.), Gessler (F.), Queseth (O.), Stridh (R.), Unbehaun (M.), Wu (J.), Zander (J., Flament (M.), 4thgeneration wireless infrastructures: scenarios and research challenges. IEEE Personal Communications magazine (December 2001), 25-31.

(6) Bueno De Mesquita (B.), Political forecasting: an expected utility method. In Bueno de Mesquita, B., Stockman, F. (Eds) European Community decision making. Yale University Press (1994), 71-104.

[7] CONSTANCE (S.), GOWER (J.), A value chain perspective on the economic drivers of competition in the wireless lelecommunications industry. Thesis MIT Sloan School (2001).

[8] Constantiou (I.), Scenarios for Mobile Commerce in 2006 - Mobicom. European Fifth Framework Project 1ST-1999-21000 (2002).

[9] Courtney (H.), Kirkland( J.), Viguerie (P.), Strategy under uncertainty, McKnsey Quarterly, December 2001, p. $5-14(2001)$ 
[10] Daugherty (W.), Eugster (C.), Roche (P.), Stowall (T.), Information unleashed: the coming of wireless data, McKinsey Quarterly, 2 (1999), p. 88-99

[11] Devine, (A.), HolmQvist (S.), Mobile internet content providers and their business models. Master thesis. The Royal Institute of Technology, Stockholm (2001).

[12] Ducatel (K.), Bogdanowicz (M.), Scapolo (F.), LejJten (J.), Bergelman (J.), Scenarios for Ambient Intelligence in 2010 - ISTAG. Information Society Technologies Project (2001).

[13] EU. eMobility. Report of the conference on mobility in the knowledge economy. European Community - IST. Goteborg (December 2001), 115p.

[14] FEITEN (B.), Enabling Technologies and usage Scenarios for Information Services on UMTS - MobilUS. EURESCOM (2001).

[15] Flament (M.), Gessler (F.), Lagergren (F.), Queseth (O.), Stridh (R.), Unbehaun (M.), Wu (J.), Zander (J.), Telecom scenarios 2010 - a wireless infrastructure perspective. Royal Institute of Technology (1998).

[16] Giussani (B.), Roam. making sense of the wireless Internet. Random House (2001), 320 p.

[17] Godet (M.), The art of scenarios and strategic planning: tools and pitfalls, Technological Forecasting and Social Change, 65 (September 2000) 3-22

[18] Gordin (J.), Akkermans (J.), Van Vliet (J.), What's in an electronic business model?, in Knowledge Engineering and Knowledge Management - Methods, Models, and Tools, LNAI 1937 (2000), p. 257-273.

[19] HAN (S.), HARKKe (V.), LANDOR (P.), Rossi DE MoI (R.), A Foresight Framework for Understanding the Future of Mobile Commerce, IFIP DsiAge'2002 (July 2002).

[20] Hubaux (J.), Gross (T.), Le Boudec (J.), Vetterli (M.), Towards self-organized mobile ad hoc networks: The Terminodes project. IEEE Communications Magazine, (January 2001).

[21] Kalakota (R.), m-Business - The Race of Mobility. McGraw Hill (2002), 302 p.

[22] KARLSON (B.), Bria (A.), Lind (J.), Lönqvist (P.), NorLin (C.), Wireless Foresight - Scenario of the Mobile World in 2015. Royal Institute of Technology (2002)

[23] KeEn (P.), MACKInTOSH (R.), The freedom economy - Changing the mCommerce edge in the era of the wireless Internet. McGraw Hill (2001), 257 p.

[24] Kviselius (N.), Swedish mobile Internet companies, Stockholm School of Economics (2001).

[25] KYRKI (A.), Scenario analysis in evaluation of emerging technology - Case Bluetooth. Thesis Lappeenranta University of Technology (2001).

[26] Lai (J.), Mohan (A.), GuSTAFson (G.), Understanding the emerging mobile commerce marketplace: our hypotheses on the structure of the marketplace in 2005, Arthur D. Little (2000).

[27] LEHNER (F.), WATSON (R.), From e-commerce to m-commerce: research directions. Working paper. University of Regensburg: Chair of Business Informatics (2001).

[28] LyYtinen (K.), Yoo (Y.), The next wave of nomadic computing: a research agenda for information systems research. Sprouts: Working Papers on Information Environments, Systems and Organizations, 1 (Summer 2001).

[29] MüLleR-VeERSE (F.), et al. UMTS report - An investment perspective, Durlacher (2001), 144 p.

[30] Mueller (M.), Lovelock (P.), The wTo and China's ban of foreign investment in telecommunication services: a game theoretic analysis. Telecommunication Policy, 24, 8/9 (2000), 731-759.

[31] Osterwalder (A.), Pigneur (Y.), An e-business model ontology for modelling e-business. to appear in Proc. $15^{\text {th }}$ Bled Electronic Commerce Conference (June 2002).

[32] Pedersen (P.), Ling (R.), Mobile end-user adoption studies: a selective review. Scandinavian Journal of Information Systems (April 2002).

[33] Pfeffer (J.), SalanciK (G.), The external Control of Organization. Harper \& Row (1978).

[34] Revaz (E.), Pigneur (Y.), Models for designing business situations in the context of mutations, in Intl Journal of Intelligent Systems in Accounting, Finance \& Management, 7 (1998), 53-66.

[35] SIDERIS (J.), The use of scenario planning methodology in mobile business as a learning tool, Proceedings $2^{\text {nd }}$ M-business conference, (2002).

[36] SIKÏO (T.), The role of Bluetooth technology in transforming the value network of ICT industry. Thesis Lappeenranta University of Technology (2001).

[37] Stabell (C.), Fueldstad (D.), Configuring value for competitive advantage: on chains, shops, and networks, Strategic Management Journal, 19 (1998), 413-437

[38] StOckman (F.), VAN OOSTEN (R.), The exchange of voting positions: an object-oriented model of policy networks. In Bueno de Mesquita, B., Stockman, F. (Eds) European Community decision making. Yale University Press (1994), 105-128.

[39] SCHWARTz (P.), The Art of Long View. Currency. DoubleDay (1991).

[40] Tarasewich (P.), Nickerson (R.), Warkentin (M.), Issues in Mobile E-Commerce, Communication of the Association for Information Systems, 8, January (2002), 41-64.

[41] Tatnall (A.), Gilding (A.), Actor-Network Theory and Information System Research. Proc. 10th Australian Conference on Information Systems (1999). 
[42] Thorngren (B.), Public WLAN - The interaction between venues and wLSPs. Master thesis, Lund School of Economics and Management, (2002).

[43] Varshney (U.), VetTer (R.), A framework for the emerging mobile commerce applications, Proc. 34th Hawaii International Conference on System Sciences, (January 2001).

[44] Vittet-PhilipPe (P.), Navarro (J.), Mobile e-business (m-commerce) - State of play and implications for European enterprise policy. European Commission: DG Enterprise (2000).

[45] WWRF. The Book of Visions 200l - Visions of the wireless world. Wireless World Research Forum, December $(2001), 275 \mathrm{p}$.

[46| YU (E.), LIU (L.), LI (Y.), Modeling strategic actor relationship to support intellectual property management. International Conference on Conceptual Modeling (2001).

\section{APPENDIX 1: WIRELESS ACTORS' MAP}

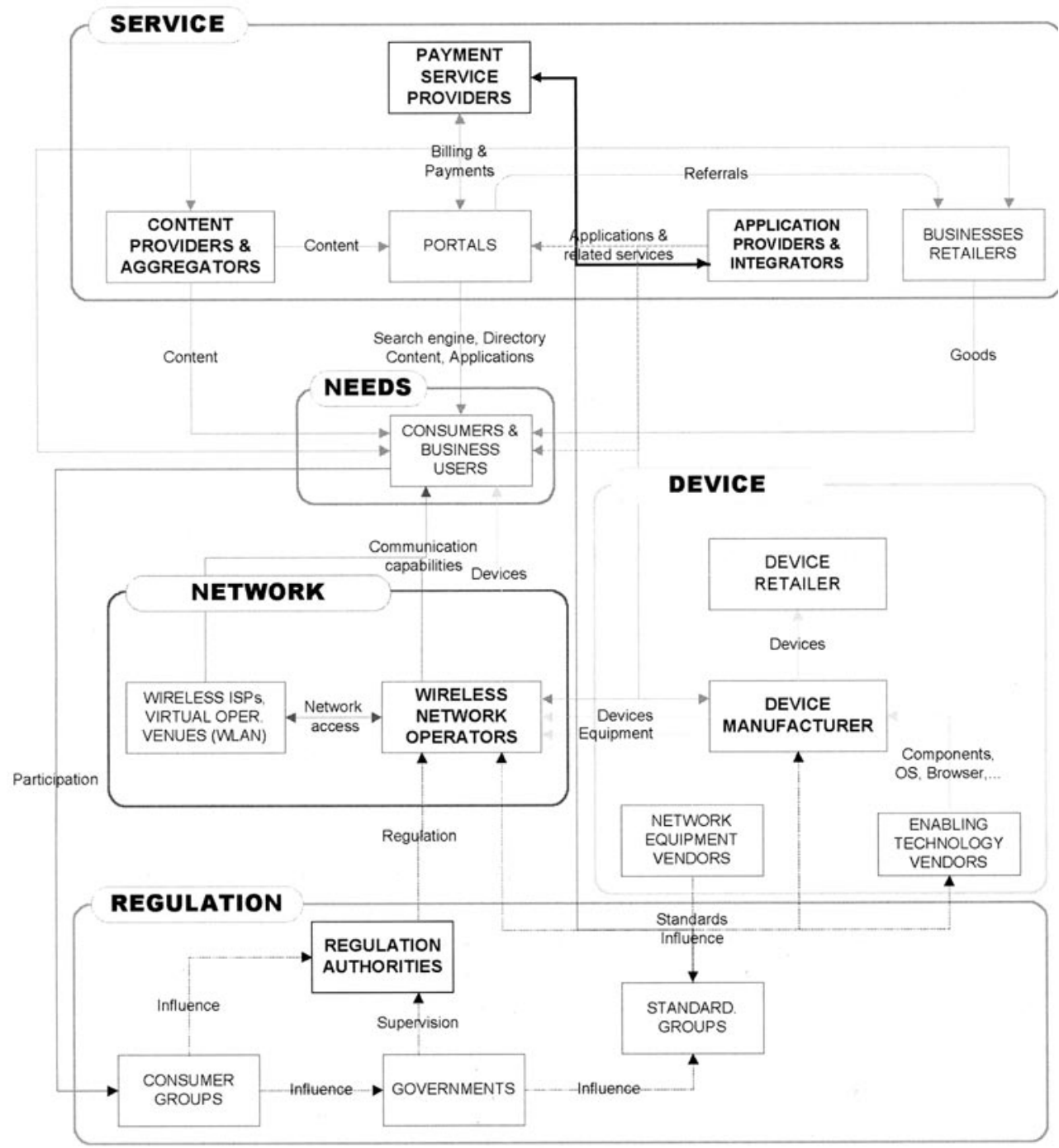

